\title{
Time-restricted feeding and the realignment of biological rhythms: translational opportunities and challenges
}

\author{
Jag Sunderram ${ }^{1}$, Stavroula Sofou ${ }^{2,3}$, Kubra Kamisoglu $^{3}$, Vassiliki Karantza ${ }^{4}$ and loannis P Androulakis ${ }^{2,3^{*}}$
}

\begin{abstract}
It has been argued that circadian dysregulation is not only a critical inducer and promoter of adverse health effects, exacerbating symptom burden, but also hampers recovery. Therefore understanding the health-promoting roles of regulating (i.e., restoring) circadian rhythms, thus suppressing harmful effects of circadian dysregulation, would likely improve treatment. At a critical care setting it has been argued that studies are warranted to determine whether there is any use in restoring circadian rhythms in critically ill patients, what therapeutic goals should be targeted, and how these could be achieved. Particularly interesting are interventional approaches aiming at optimizing the time of feeding in relation to individualized day-night cycles for patients receiving enteral nutrition, in an attempt to re-establish circadian patterns of molecular expression. In this short review we wish to explore the idea of transiently imposing (appropriate, but yet to be determined) circadian rhythmicity via regulation of food intake as a means of exploring rhythm-setting properties of metabolic cues in the context of improving immune response. We highlight some of the key elements associated with his complex question particularly as they relate to: a) stress and rhythmic variability; and b) metabolic entrainment of peripheral tissues as a possible intervention strategy through time-restricted feeding. Finally, we discuss the challenges and opportunities for translating these ideas to the bedside.
\end{abstract}

\section{Introduction}

Biological rhythms are major determinants of behavioural outcome [1,2] and are controlled by a tightly regulated network of genes and proteins entrained by external signals (light and food). The suprachiasmatic nucleus $(\mathrm{SCN})$ is the fundamental, central, regulator of circadian rhythmicity (biological rhythms of, roughly, $24 \mathrm{~h}$ period) and is considered the master clock designed to align, and coordinate the independent, self-sustained, peripheral oscillators (a.k.a. peripheral clocks) found in every cell, tissue and organ [3-6]. In that respect, understanding the mechanisms by which the various pacemakers interact to coordinate functions becomes a critical question [7]. Despite the fact that all peripheral clocks effectively utilize the same time-keeping machinery [8-11] (Figure 1) each peripheral entity is impacted by unique stimuli capable of

\footnotetext{
*Correspondence: yannis@rci.rutgers.edu

${ }^{2}$ Biomedical Engineering Department, Rutgers University, Piscataway, NJ 08854, USA

${ }^{3}$ Chemical \& Biochemical Engineering Department, Rutgers University, Piscataway, NJ 08854, USA

Full list of author information is available at the end of the article
}

setting clock rhythmicity locally, directly or indirectly. As such, core physiological functions are strongly impacted by the appropriate alignment of peripheral clocks to central $(\mathrm{SCN})$ rhythms $[12,13]$ likely mediated via circulating hormones $[14,15]$. While biological rhythms convey anticipatory signals priming the host for periods of food intake, increased activity and rest [16-18] (Figure 2) the loss of these rhythms has deleterious effects on overall health [19]. The interplay between a host's well-being and its biological rhythms is critical and bi-directional: disrupted rhythms impact the response to stress whereas stress alters the characteristics of biological rhythms [20-22].

Emerging evidence suggesting that rhythmic signals play a major role in immune [25-27] and metabolic [28] functions naturally leads to the possibility of exploring biological rhythms as targets of intervention strategies, and in particular in the context of intensive care units (ICU) where non-natural light schedules and time-invariant nutritional and/or pharmaceutical interventions may deprive patients of the rhythmic cues necessary to maintain appropriate biological rhythmicity during the recovery phase $[29,30]$ 


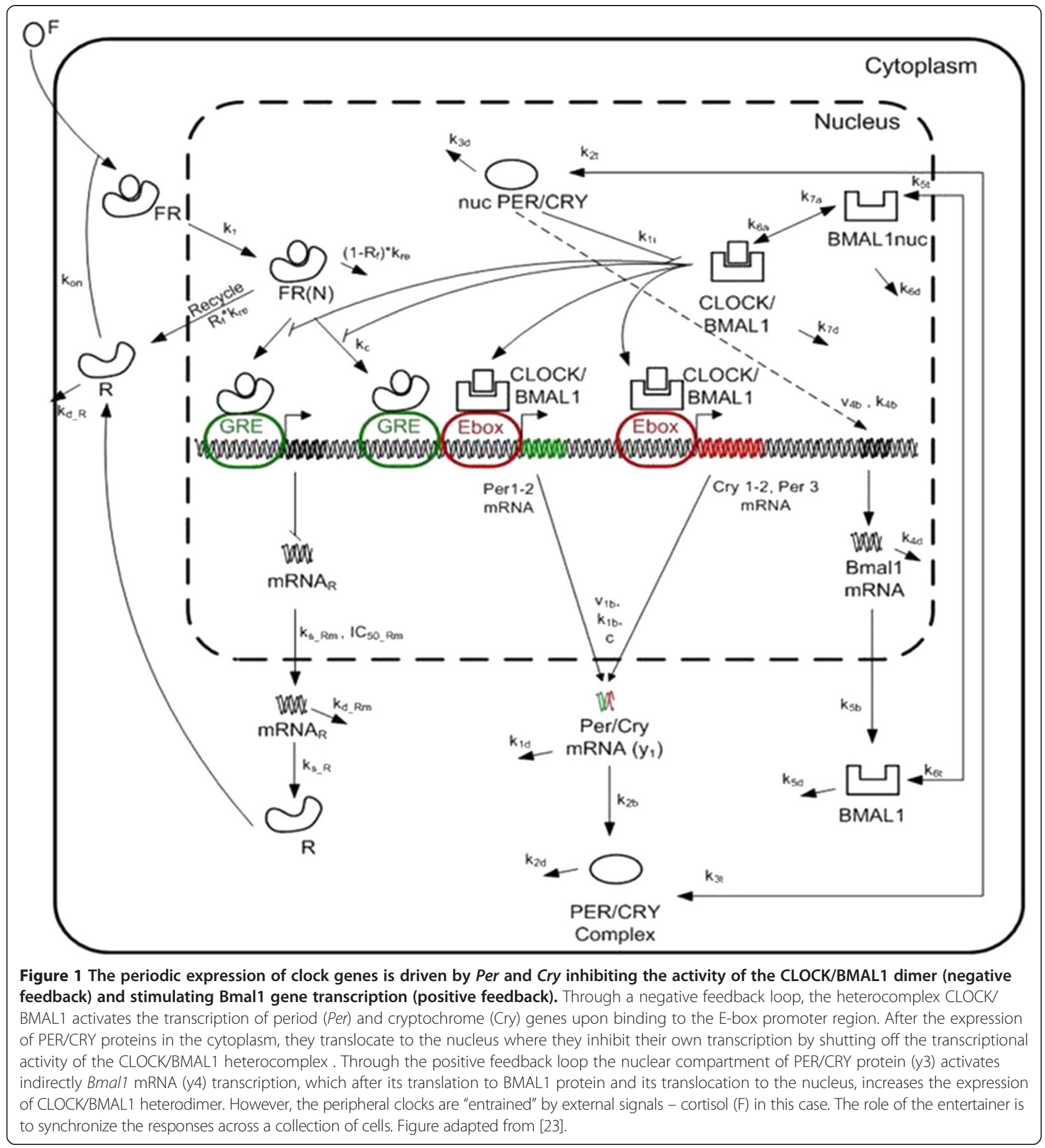

and loss of entraining inputs may significantly impact recovery [10,31-34]. In fact circadian abnormalities correlate with severity of illness and outcome [35]. Due to the strong role rhythmicity plays in recovering from trauma $[36,37]$, its regulation and realignment are emerging as potentially critical controllers influencing patient outcome by regulating entraining signals in a non-invasive manner. Circadian cues that control rest cycles and metabolism are primarily driven by light and food [38,39]. These play a fundamental role in that they maintain proper synchrony between the peripheral clocks (Figure 3). The importance of maintaining good coordination between the peripheral oscillators is so critical that physicians have speculated that "[...] healthy organs behave as biological oscillators, which couple to one another during human development, and that this orderly coupling is maintained through a 


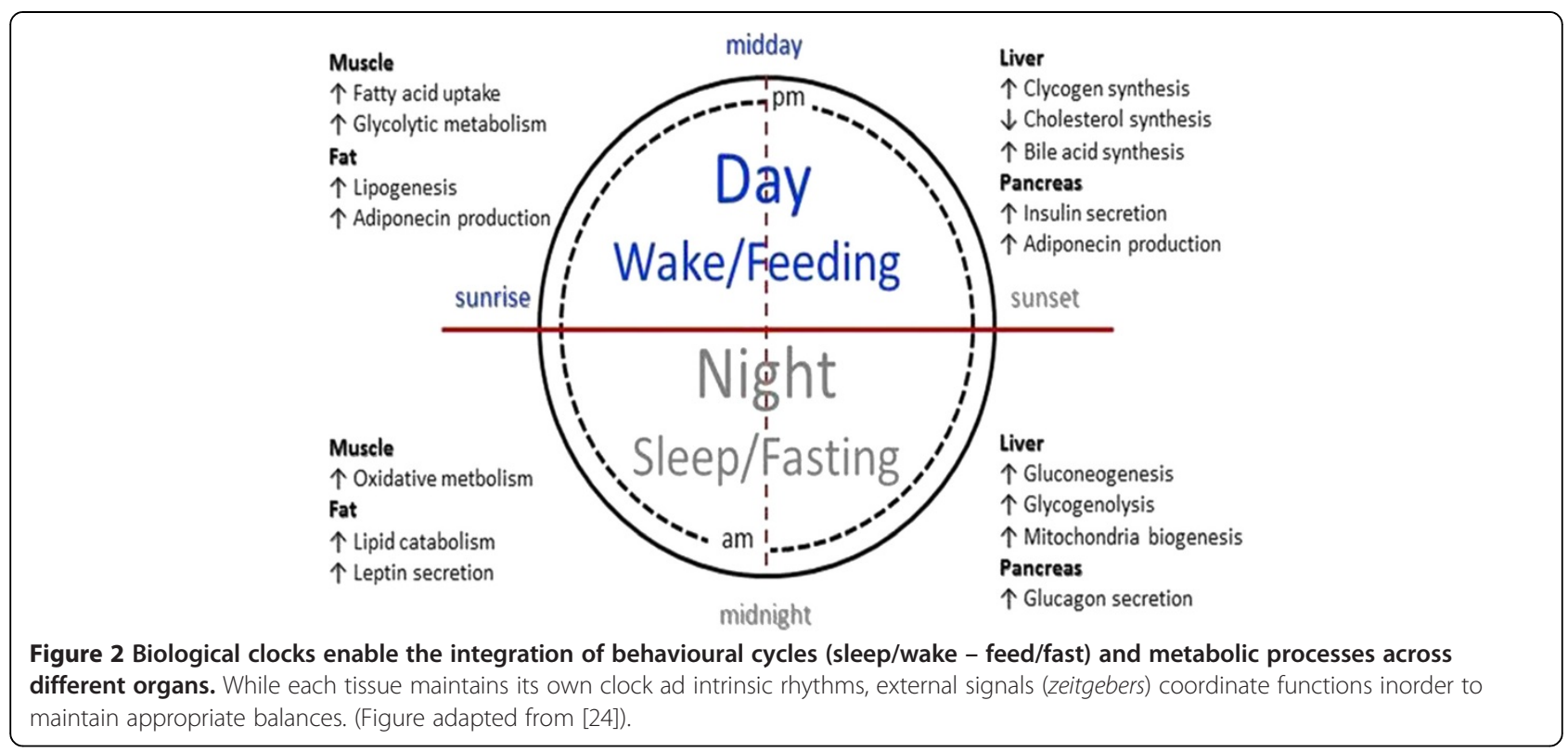

communications network, including neural, humoral, and cytokine components. [We] suggest that the systemic inflammatory response syndrome initiates disruption of communication and uncoupling, and further suggest that progression into the multiple organ dysfunction syndrome reflects progressive uncoupling that can become irreversible. Resolution of the inflammatory response and reestablishment of the communications network are necessary but may not be, by itself, sufficient to allow organs to appropriately recouple" [40].
Exploring these cycles in order to realign patients' biological rhythms during the recovery phase may prove to be highly rewarding in terms of outcome [41]. Therefore, understanding the mechanisms that entrain the central and peripheral clocks, and the ways in which these rhythms influence the ability of the host organism to respond to, and recover from, external threats and challenges is critical to developing new models of patient care capable of engaging these rhythms in an attempt to, potentially, improve outcome. It must be noted that although it is

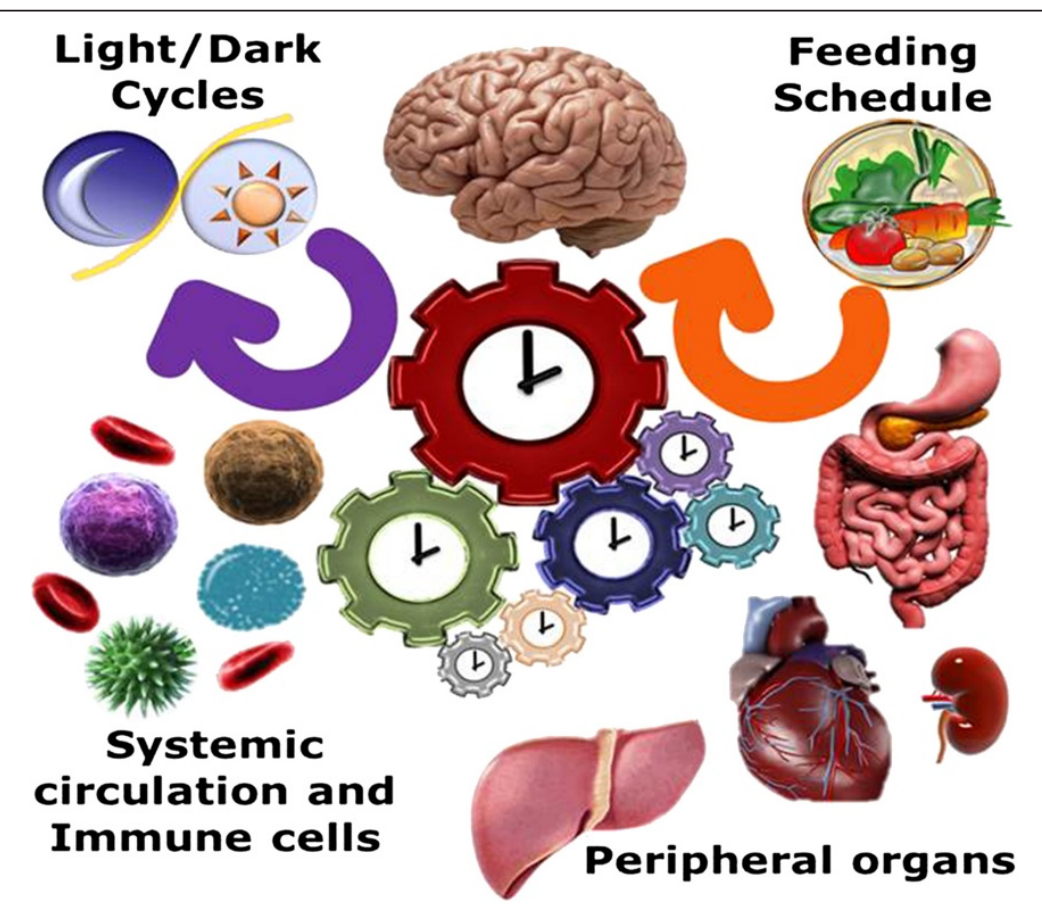

Figure 3 Systemic signals act as coordinators of peripheral oscillators maintaining synchrony of function and health. 
well established that ICU patients have abnormal circadian patterns $[35,42]$ the overall environment in the ICU, including the patient's condition, the lighting and noise levels in ICU as well as - and likely very importantly - the treatment the patient receives, induces significant circadian alterations $[43,44]$.

In this short review we focus on one particular approach to resetting biological rhythmicity in the context of timerestricted feeding (TRF; access to food is restricted for specific time intervals during the day without calorie restrictions) and explore the possibility of pursuing circadian re-alignment via nutritionally-inspired interventions. Although the focus of the review is on the implications of restoring circadian rhythms we should point out that appropriate sampling and analysis of biochemical and physiological circadian data requires careful design and execution and these have been the subject of numerous excellent reviews [45].

\section{Circadian reprogramming as an intervention strategy: opportunities for time-restricted feeding} Stress-induced loss of circadian rhythmicity

Evidence establishing the strong links between biological rhythms and stress response is overwhelming and, by now, very well established and accepted [14,46]. However, the translational implications, opportunities and challenges of how to manipulate rhythms in an ICU environment are only now beginning to emerge in the scientific discourse [30]. A number of recent, and older, reviews have discussed the connections between immune function and biological rhythms [46] where the bi-directional relationship between disrupted rhythms and immune dysfunction; and its implication on the bedside have been clearly identified [36,37]. What is even more interesting is the fact that we begin to realize that circadian dysfunction following stress may have long lasting ramifications [47] pointing to possible sources of comorbidities. In fact, it has been argued that different procedures impact post-operative circadian disruption in a differential manner, thus affecting recovery, raising the possibility of guiding operative procedures based on their capacity to minimize impact on biological rhythms [48]. Clinical studies specifically emphasized that biological night and day cycles (measured by urinary 6-sulfatoxymelatonin) were phase-delayed and normal features of sleep were lacking (REM sleep was identified only in 2 patients out of 21) in the critical care patients [49]. Studies on patients undergoing elective maxillofacial surgery showed that strengthening circadian rhythms in anticipation of disruption following surgery can be efficacious for improving the recovery phase. Patients whose circadian rhythms were adjusted pre-operatively by combined sleep/wake cycle alteration and timed food and caffeine ingestion had reduced disruption in their body temperature cycles throughout their recovery in comparison to the control group [50].

One of the most active areas of research pointing directly to circadian disruption and biological rhythm-setting interventions relate to mood disorders [51-55]. A vast literature exists on enhancing circadian rhythms for treating depression, bipolar disorder and other related mood disorders either via pharmacological (melatonin) [55,56] or non-pharmacological means (light) [57] aimed at boosting circadian rhythms.

\section{Circadian (re)alignment and time-restricted feeding}

Time restricted feeding (TRF) is essentially imposing rhythms on nutrient availability. Entrainment by TRF has generated significant interest due to the possibility of synchronizing peripheral clocks without clear influences on (or from) the central pacemaker (SCN) $[28,58]$. It has been speculated that restricted feeding (RF) entrains rhythms in peripheral tissues (liver and lung) [6] is likely independent of the SCN. These works challenge the basic hierarchical paradigm that light entrains the SCN which subsequently entrains the peripheral clocks and emphasized the role of RF as an entraining signal. The hypothesis of independently entrained peripheral clocks has been further reinforced by the observation that even lesions in brain nuclei do not eliminate food anticipatory activity, thus pointing to likelihood of a distributed system maintaining and regulating food-anticipatory activities $[59,60]$. One of the main justifications is that when food accessibility adopts specific rhythmic characteristics so will the physiology and behaviour to match nutritional resource availability [61]. It has been shown that feeding mice during the day completely reverses the phase of circadian oscillators (specifically, four clock components, Per1, Per2, Per3, Cry1; and the two circadian transcription factors DBP and Rev-erb $\alpha$ ) in multiple peripheral cells (liver, kidney, heart and pancreas), but has little if any effect on the central oscillator in the SCN [62]. However, we must point out that RF entrains the rhythm of clock protein Per2 even in the SCN as was shown in studies that eliminated photic stimulation by keeping mice in constant darkness [63], or at constant light conditions [64], thus raising the possibility of peripheral oscillators resetting the central clock.

In a carefully designed study of a murine obesity model [53] the authors convincingly show the intimate relationship between the signalling and transcriptional components of energy metabolism and the circadian system. The study hypothesized that TRF improves diurnal rhythms; drives lipid homeostasis while preventing weight gain, hepatosteatosis and liver damage; improves adipose homeostasis and reduces inflammation. The study demonstrated that preserving natural feeding rhythms significantly dampens metabolic disruption induced by a high fat diet, including 
improving oscillations of the liver circadian clock components. Therefore, while the total calorie intake and food composition (high fat) remained constant, the study clearly demonstrated that an apparent lifestyle, i.e.,non-pharmacological, intervention prevented obesity, and related comorbidities, possibly by resetting metabolic cycles. The role of food-anticipatory activity has also been explored with a focus on energy metabolism, defined by oxygen consumption [65]. Animals were allowed access to food for only few hours during either the light or the dark phases. Locomotor activity, body temperature, clock gene expression in liver and energy metabolism were recorded and their changes assessed as the time window over which food became available was changing. Continuous monitoring of energy metabolism and core body temperature indicated expected, robust diurnal rhythmic characteristics but also rapid re-entrainment and adaptation to restricted food access.

A series of publications has focused on comparing protein synthesis under a continuous and, a likely more physiologically realistic, intermittent bolus feeding regimen, delivered by orogastric tube, in neonatal pigs in the context of regulating protein synthesis [66-68]. The analysis demonstrated that intermittent feeding (delivered every $4 \mathrm{hrs}$ as a bolus feed) enhances muscle protein synthesis by imposing pulsatile patterns of amino-acid and insulin-induced translation initiation. In this very interesting series of papers it has been argued that bolus feeding promotes a more physiological surge of intestinal hormones. The studies effectively hypothesize that "[...] cyclic surge of amino acids and insulin is needed to maximally stimulate protein synthesis in skeletal muscle" and that "[...] bolus compared to continuous feeding has been advocated to promote more normal feed-fast hormonal profiles". It has been further demonstrated that either advancing or delaying meal time in young adult mice results in reversible alterations of temperature and overall cage activities [69]. Longer time restriction (one week) alters rhythms in glucose, triglyceride and HDL levels. Food restriction results in behavioral arousal in anticipation of food presentation and induces a shift in the circadian phase of many physiological variables, likely independent of the SCN. As such, RF is expected to exert changes in organs "handling nutrients" (such as liver). As previous work had suggested RF could be associated with significant stress due to hyperphagia, In a study examining the effect of restricted feeding on stress markers, no marked changes in body weight, retroperitoneal decrease in lipid deposits and peak in glucocorticoids accompanying expectation to food access were identified [70]. Given the probable relationship between stress and metabolic alterations (in this case interest was in liver) the study explored whether an increase in acute phase proteins (APR) or pro-inflammatory state occurred after 2 weeks of $2 \mathrm{hr}$ food restriction. The "positive control" for APR consisting of a group injected with LPS showed a significant increase in systems APR while neither the ad libitum nor restricted feeding induced a marked increase in any of the inflammatory markers. Furthermore, a marked change in the diurnal patterns of circulating cytokines was observed as a consequence of RF. The authors advance an interesting hypothesis stating that RF may establish a distinctive state ("rheostatic response" earlier introduced in [71]) likely enabling the system to adopt a transient functional state "change in set-point", boosting the rhythms and the overall fitness of the host.

\section{Time-restricted feeding and disease progression}

Peripheral circadian de-synchrony may be an early indicator of metabolic disruption in shift workers due to sleep deprivation mediated disruption of circadian rhythms. By extension, strengthening the peripheral circadian rhythm, by imposing metabolic rhythms via limiting food intake during the night, may counteract comorbidities seen in human shift workers [72]. This study further implies that the manipulation of circadian rhythms need not be such that it aims at restoring the homeostatic nature of the internal clock. Rather it implies that, at least in the short term, strengthening other rhythmic frequencies may be more beneficial.

Particularly interesting is the work investigating the effect of resetting circadian clocks in peripheral tissues using non-photic signals on tumor growth rate in rats [73,74]. Restricting the timing of meals to light time in contrast to restricted feeding during the night (active phase of rats) thereby, imposing a reversed metabolic rhythm, induced, what is referred to as, "internal desynchronization" (described as loss of phase relationship between central light entrained - and peripheral clocks) resulted in prolonged survival and slowed down tumor growth. The authors speculate that meal timing during the light period amplifies host rhythms and assigns their peak in a time window when the tumor is most susceptible to hostmediated control and that tumor growth is hampered when the internal (metabolic) clock adopts specific rhythmic characteristics, interestingly the opposite of what would have been otherwise considered "natural". Therefore, the emerging hypothesis is that, a radically different metabolic rhythmicity appears to be most effective at least in the short term.

\section{Restricted-time feeding vs. calorie restriction}

It is important to draw a distinction between timerestricted feeding and caloric restriction. The former entails the delivery of a certain amount of calories albeit at specific time intervals of specific duration. Therefore subjects still receive a standard nutritional intake. Calorie restriction entails an overall reduction in caloric intake, albeit without malnutrition. While evidence for the benefits of calorie restriction in animals has been promising, 
the issue as it relates to humans is still debated as conducting long term studies assessing the implications of prolonged calorie restriction in a controlled manner is rather complicated [75]. Although studies have shown calorie restriction improves post-trauma outcomes [76-78], it is likely that the long term effects of calorie restriction are related to alterations of biological mechanisms responsible for maintenance of health [79]. Recent work has indicated the possibility of caloric restriction impacting circadian clocks as well [80]. However, it is argued that this may be a secondary effect of calorie restriction resulting in time restricted feeding imposing specific rhythms on metabolic function and entraining peripheral clocks. Nevertheless, the focus of this discussion is on TRF and not on calorie restriction.

\section{Clinical studies comparing continuous vs. bolus feeding} A number of fairly comprehensive clinical studies have considered the impact of temporal delivery of enteral feeding in critical patients [81-88]. Although these studies have to be acknowledged in the context of our discussion, one should be aware of the fact that clinical studies comparing continuous vs. bolus feeding were motivated mostly by the need to address some of the key practical limitations associated with delivering nutritional support, such as interruptions of continuous feeding leading to an inability to achieve nutritional goals, gastrointestinal complications, modulation of aspiration pneumonia, stool frequency etc., rather than as an attempt to capitalize on potentially advantageous physiological and/or biochemical routes linking metabolic rhythms and immune response. Earlier studies examined various parameters influenced by delivering enteral nutrition in the form of either continuous or bolus (intermittent) delivery and the conclusions are still debated in the clinical community [84]. Studies comparing continuous to intermittent tube feeding in adult burn patients concluded that patients continuously fed had reduced stool frequency and time required to achieve nutritional goals. More recent studies, however, despite minor differences in specific goals and targets, in general do not provide evidence of significant difference in terms of patient outcome. Results show that patients intermittently fed have a higher total intake volume, are extubated earlier, and have a lower risk of aspiration pneumonia. Postoperatively, feeding at night only is more energy efficient than is feeding continuously for $24 \mathrm{~h}$, but is associated with poorer nitrogen balance [82]. In one of the very few studies which complemented intermittent feeding in a clinical setting with monitoring of biomarkers, the observed decrease in urinary catecholamine secretion indicated a possible role of sympatho-adrenal mechanisms. This study provides a link between feeding patterns and putatively modulated pathways. However, no studies have been performed where time restricted feeding has been compared to either bolus or continuous feeding in the ICU.

\section{Concluding remarks}

Time restricted delivery of metabolites imposes rhythmic availability of nutrients which resets peripheral clocks in a way that potentially exerts a positive impact on the immune response. Recent clinical evidence indicates that restoring circadian rhythms in critically ill patients is important. We hypothesize that providing circadian cues in the ICU could be explored as a mechanism to improve

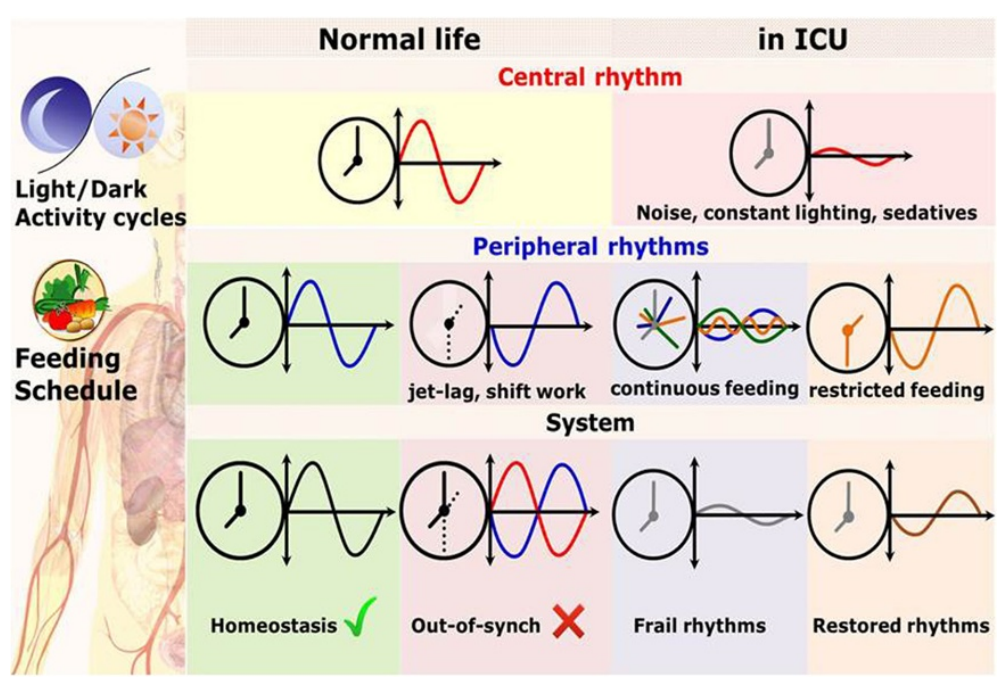

Figure 4 Robust circadian entrainment characterizes homeostasis, whereas disruptions (amplitude and phase) characterize stressful critical conditions. Whereas in homeostasis circadian rhythms are properly aligned with clearly identifiable phase locking, circadian disruption shifts peripheral clock rhythms. Restoration of peripheral rhythms, including nutritionally-driven metabolic rhythms through time-restricted feeding will re-entrain the system and provide appropriate systemic cues. 
ICU outcome by reinforcing appropriate rhythms of hormonal release [30,34] (Figure 4). As it is becoming increasingly more evident that exploring alternatives measures to re-establish circadian patters of molecular expression via non-pharmacological means could hold significant potential, feeding entrainment through the possibility of optimizing the time of feeding in relation to the light/dark cycle for patients receiving enteral nutrition appears to beg for more investigation [29].

In this brief review we elaborated on the idea that establishing abolished rhythms would have a beneficial effect on the host response to stress. We highlighted some of the key elements associated with this complex question particularly as they relate to: a) stress and rhythmic variability; and b) metabolic entrainment of peripheral tissues as a possible intervention strategy through time-restricted feeding. Positive effects have been shown in the context of psychological stress, mood disorders etc., using either pharmacologic agents, aiming at restoring circadian signals, or using photic signals to activate the central pace maker. The question, however, remains whether imposing appropriate metabolic rhythms, likely not maintaining homeostatic phase relations with the central clock, through time-restricted feeding would lead to beneficial entrainment of peripheral clocks resulting in improved health outcomes with a host under stress.

\section{Competing interests}

The authors declare that they have no competing interests.

\section{Authors' contributions}

JS, SS, KK, VK edited the manuscript; IPA conceived the idea, prepared and edited the manuscript. All authors read and approved the final manuscript.

\section{Author details}

'Department of Medicine, Division of Pulmonary and Critical Care Medicine, Rutgers - Robert Wood Johnson Medical School, New Brunswick, NJ 08901, USA. ${ }^{2}$ Biomedical Engineering Department, Rutgers University, Piscataway, NJ 08854, USA. ${ }^{3}$ Chemical \& Biochemical Engineering Department, Rutgers University, Piscataway, NJ 08854, USA. ${ }^{4}$ Rutgers Cancer Institute of New Jersey, Rutgers University, New Brunswick 08901, USA.

Received: 21 December 2013 Accepted: 10 March 2014 Published: 28 March 2014

\section{References}

1. Reppert SM, Weaver DR: Coordination of circadian timing in mammals. Nature 2002, 418:935-941.

2. Lowrey PL, Takahashi JS: Mammalian circadian biology: elucidating genome-wide levels of temporal organization. Annu Rev Genomics Hum Genet 2004, 5:407-441.

3. Liu C, Weaver DR, Strogatz SH, Reppert SM: Cellular construction of a circadian clock: period determination in the suprachiasmatic nuclei. Cell 1997, 91:855-860.

4. Kohsaka A, Bass J: A sense of time: how molecular clocks organize metabolism. Trends Endocrinol Metab 2007, 18:4-11.

5. Grechez-Cassiau A, Rayet B, Guillaumond F, Teboul M, Delaunay F: The circadian clock component BMAL1 is a critical regulator of p21WAF1/CIP1 expression and hepatocyte proliferation. J Biol Chem 2008, 283:4535-4542.

6. Stokkan K-A, Yamazaki S, Tei H, Sakaki Y, Menaker M: Entrainment of the circadian clock in the liver by feeding. Science 2001, 291:490-493.
7. Schibler U, Sassone-Corsi P: A web of circadian pacemakers. Cell 2002, 111:919-922.

8. Eisele L, Prinz R, Klein-Hitpass L, Nuckel H, Lowinski K, Thomale J, Moeller LC, Duhrsen U, Durig J: Combined PER2 and CRY1 expression predicts outcome in chronic lymphocytic leukemia. Eur J Haematol 2009, 83:320-327.

9. Everson CA: Functional consequences of sustained sleep deprivation in the rat. Behav Brain Res 1995, 69:43-54.

10. Fu L, Pelicano H, Liu J, Huang P, Lee C: The circadian gene Period2 plays an important role in tumor suppression and DNA damage response in vivo. Cell 2002, 111:41-50.

11. Gekakis N, Staknis D, Nguyen HB, Davis FC, Wilsbacher LD, King DP, Takahashi JS, Weitz CJ: Role of the CLOCK protein in the mammalian circadian mechanism. Science 1998, 280:1564-1569.

12. Green CB, Takahashi JS, Bass J: The meter of metabolism. Cell 2008, 134:728-742.

13. Lamia KA, Storch KF, Weitz CJ: Physiological significance of a peripheral tissue circadian clock. Proc Natl Acad Sci U S A 2008, 105:15172-15177.

14. Arjona A, Silver AC, Walker WE, Fikrig E: Immunity's fourth dimension: approaching the circadian-immune connection. Trends Immunol 2012, 33:607-612.

15. Le Minh N, Damiola F, Tronche F, Schutz G, Schibler U: Glucocorticoid hormones inhibit food-induced phase-shifting of peripheral circadian oscillators. EMBO J 2001, 20:7128-7136.

16. Koyanagi S, Ohdo S: Alteration of intrinsic biological rhythms during interferon treatment and its possible mechanism. Mol Pharmacol 2002, 62:1393-1399.

17. Vitalini MW, de Paula RM, Park WD, Bell-Pedersen D: The rhythms of life: circadian output pathways in Neurospora. J Biol Rhythms 2006, 21:432-444.

18. Edery I: Circadian rhythms in a nutshell. Physiol Genomics 2000, 3:59-74.

19. Rana S, Mahmood S: Circadian rhythm and its role in malignancy. J Circadian Rhythms 2010, 8:3.

20. Rechtschaffen A, Bergmann BM, Gilliland MA, Bauer K: Effects of method, duration, and sleep stage on rebounds from sleep deprivation in the rat. Sleep 1999, 22:11-31.

21. Reilly DF, Westgate EJ, FitzGerald GA: Peripheral circadian clocks in the vasculature. Arterioscler Thromb Vasc Biol 2007, 27:1694-1705.

22. Haimovich B, Calvano J, Haimovich AD, Calvano SE, Coyle SM, Lowry SF: In vivo endotoxin synchronizes and suppresses clock gene expression in human peripheral blood leukocytes. Crit Care Med 2010, 38:751-758.

23. Mavroudis PD, Scheff JD, Calvano SE, Lowry SF, Androulakis IP: Entrainment of peripheral clock genes by cortisol. Physiol Genomics 2012, 44:607-621.

24. Bass J, Takahashi JS: Circadian integration of metabolism and energetics. Science 2010, 330:1349-1354.

25. Lee JE, Edery I: Circadian regulation in the ability of Drosophila to combat pathogenic infections. Curr Biol 2008, 18:195-199.

26. Paladino N, Leone MJ, Plano SA, Golombek DA: Paying the circadian toll: the circadian response to LPS injection is dependent on the Toll-like receptor 4. J Neuroimmunol 2010, 225:62-67.

27. Silver AC, Arjona A, Walker WE, Fikrig E: The circadian clock controls tolllike receptor 9-mediated innate and adaptive immunity. Immunity 2012, 36:251-261.

28. Feillet CA, Albrecht $U$, Challet E: "Feeding time" for the brain: a matter of clocks. J Physiol Paris 2006, 100:252-260.

29. Carlson DE: Are you having a good day: a passing nicety or a fundamental question in the intensive care unit? Crit Care Med 2012, 40:344-345.

30. Chan MC, Spieth PM, Quinn K, Parotto M, Zhang H, Slutsky AS: Circadian rhythms: from basic mechanisms to the intensive care unit. Crit Care Med 2012, 40:246-253.

31. Cao Q, Gery S, Dashti A, Yin D, Zhou Y, Gu J, Koeffler HP: A role for the clock gene Per1 in prostate cancer. Cancer Res 2001, 69:7619-7625.

32. Filipski E, Levi F: Circadian disruption in experimental cancer processes. Integr Cancer Ther 2009, 8:298-302.

33. Bornstein SR, Licinio J, Tauchnitz R, Engelmann L, Negrão AB, Gold P, Chrousos GP: Plasma leptin levels Are increased in survivors of acute sepsis: associated loss of diurnal rhythm in cortisol and leptin secretion. J Clin Endocrinol Metabol 1998, 83:280-283.

34. Carlson DE, Chiu WC: The absence of circadian cues during recovery from sepsis modifies pituitary-adrenocortical function and impairs survival. Shock 2008, 29:127-132. 110.1097/shk.1090b1013e318142c318145a318142.

35. Gazendam JA, Van Dongen HP, Grant DA, Freedman NS, Zwaveling JH, Schwab RJ: Altered circadian rhythmicity in patients in the ICU. Chest 2013, 144:483-489. 
36. Lowry SF: The evolution of an inflammatory response. Surg Infect (Larchmt) 2009, 10:419-425.

37. Lowry SF: The stressed host response to infection: the disruptive signals and rhythms of systemic inflammation. Surg Clin North Am 2009, 89:311-326. vii.

38. Cardone L, Hirayama J, Giordano F, Tamaru T, Palvimo JJ, Sassone-Corsi P: Circadian clock control by SUMOylation of BMAL1. Science 2005, 309:1390-1394.

39. Cassone VM: Effects of melatonin on vertebrate circadian systems. Trends Neurosci 1990, 13:457-464.

40. Godin PJ, Buchman TG: Uncoupling of biological oscillators: a complementary hypothesis concerning the pathogenesis of multiple organ dysfunction syndrome. Crit Care Med 1996, 24:1107-1116.

41. Taguchi T, Yano M, Kido Y: Influence of bright light therapy on postoperative patients: a pilot study. Intensive Crit Care Nurs 2007, 23:289-297.

42. Mundigler G, Delle-Karth G, Koreny M, Zehetgruber M, Steindl-Munda P, Marktl W, Ferti L, Siostrzonek P: Impaired circadian rhythm of melatonin secretion in sedated critically ill patients with severe sepsis. Crit Care Med 2002, 30:536-540.

43. Wenham T, Pittard A: Intensive care unit environment. Cont Educ Anaesth Crit Care Pain 2009, 9:178-183.

44. Campbell IT, Minors DS, Waterhouse JM: Are circadian rhythms important in intensive care? Intensive Care Nurs 1986, 1:144-150.

45. Refinetti R, Lissen GC, Halberg F: Procedures for numerical analysis of circadian rhythms. Biol Rhythm Res 2007, 38:275-325.

46. Logan RW, Sarkar DK: Circadian nature of immune function. Mol Cell Endocrinol 2012, 349:82-90.

47. O'Callaghan EK, Anderson ST, Moynagh PN, Coogan AN: Long-lasting effects of sepsis on circadian rhythms in the mouse. PLoS ONE 2012, 7:e47087.

48. Gogenur I, Bisgaard T, Burgdorf S, van Someren E, Rosenberg J: Disturbances in the circadian pattern of activity and sleep after laparoscopic versus open abdominal surgery. Surg Endosc 2009, 23:1026-1031.

49. Gehlbach BK, Chapotot F, Leproult R, Whitmore H, Poston J, Pohlman M, Miller A, Pohlman AS, Nedeltcheva A, Jacobsen JH, Hall JB, Van Cauter E: Temporal disorganization of circadian rhythmicity and sleep-wake regulation in mechanically ventilated patients receiving continuous intravenous sedation. Sleep 2012, 35:1105-1114.

50. Farr $L$, Todero $C$, Boen $L$ : Reducing disruption of circadian temperature rhythm following surgery. Biol Res Nurs 2001, 2:257-266.

51. Antoch MP, Chernov MV: Pharmacological modulators of the circadian clock as potential therapeutic drugs. Mutat Res 2009, 679:17-23.

52. Albrecht U: Circadian clocks and mood-related behaviors. Ann Med 2010, 42:241-251.

53. McClung CA: Circadian rhythms and mood regulation: insights from pre-clinical models. Eur Neuropsychopharmacol 2011, 21(Suppl 4):S683-S693.

54. Hatori M, Vollmers C, Zarrinpar A, DiTacchio L, Bushong EA, Gill S, Leblanc M, Chaix A, Joens M, Fitzpatrick JA, Ellisman MH, Panda S: Time-restricted feeding without reducing caloric intake prevents metabolic diseases in mice fed a high-fat diet. Cell Metab 2012, 15:848-860.

55. Sprouse J: Pharmacological modulation of circadian rhythms: a new drug target in psychotherapeutics. Expert Opin Ther Targets 2004, 8:25-38.

56. Lanfumey L, Mongeau R, Hamon M: Biological rhythms and melatonin in mood disorders and their treatments. Pharmacol Ther 2013, 138:176-184.

57. Naus T, Burger A, Malkoc A, Molendijk M, Haffmans J: Is there a difference in clinical efficacy of bright light therapy for different types of depression? A pilot study. J Affect Disord 2013, 151:1135-1137.

58. Hara R, Wan K, Wakamatsu H, Aida R, Moriya T, Akiyama M, Shibata S: Restricted feeding entrains liver clock without participation of the suprachiasmatic nucleus. Genes Cells 2001, 6:269-278.

59. Verwey M, Amir S: Food-entrainable circadian oscillators in the brain. Eur J Neurosci 2009, 30:1650-1657.

60. Froy O: The relationship between nutrition and circadian rhythms in mammals. Front Neuroendocrinol 2007, 28:61-71.

61. Feillet CA: Food for thoughts: feeding time and hormonal secretion. J Neuroendocrinol 2010, 22:620-628

62. Damiola F, Le Minh N, Preitner N, Kornmann B, Fleury-Olela F, Schibler U: Restricted feeding uncouples circadian oscillators in peripheral tissues from the central pacemaker in the suprachiasmatic nucleus. Genes Dev 2000, 14:2950-2961.

63. Castillo MR, Hochstetler KJ, Tavernier RJ Jr, Greene DM, Bult-lto A: Entrainment of the master circadian clock by scheduled feeding. Am J Physiol Regul Integr Comp Physiol 2004, 287:R551-R555.
64. Lamont EW, Diaz LR, Barry-Shaw J, Stewart J, Amir S: Daily restricted feeding rescues a rhythm of period2 expression in the arrhythmic suprachiasmatic nucleus. Neuroscience 2005, 132:245-248.

65. Satoh Y, Kawai H, Kudo N, Kawashima Y, Mitsumoto A: Time-restricted feeding entrains daily rhythms of energy metabolism in mice. Am J Physiol Regul Integr Comp Physiol 2006, 290:R1276-R1283.

66. El-Kadi SW, Gazzaneo MC, Suryawan A, Orellana RA, Torrazza RM, Srivastava N, Kimball SR, Nguyen HV, Fiorotto ML, Davis TA: Viscera and muscle protein synthesis in neonatal pigs is increased more by intermittent bolus than continuous feeding. Pediatr Res 2013, 74:154-162.

67. El-Kadi SW, Suryawan A, Gazzaneo MC, Srivastava N, Orellana RA, Nguyen HV, Lobley GE, Davis TA: Anabolic signaling and protein deposition are enhanced by intermittent compared with continuous feeding in skeletal muscle of neonates. Am J Physiol Endocrinol Metab 2012, 302:E674-E686.

68. Gazzaneo MC, Suryawan A, Orellana RA, Torrazza RM, El-Kadi SW, Wilson FA, Kimball SR, Srivastava N, Nguyen HV, Fiorotto ML, Davis TA: Intermittent bolus feeding has a greater stimulatory effect on protein synthesis in skeletal muscle than continuous feeding in neonatal pigs. J Nutr 2011, 141:2152-2158.

69. Yoon JA, Han DH, Noh JY, Kim MH, Son GH, Kim K, Kim CJ, Pak YK, Cho S: Meal time shift disturbs circadian rhythmicity along with metabolic and behavioral alterations in mice. PLOS ONE 2012, 7:e44053.

70. Luna-Moreno D, Aguilar-Roblero R, Diaz-Munoz M: Restricted feeding entrains rhythms of inflammation-related factors without promoting an acute-phase response. Chronobiol Int 2009, 26:1409-1429.

71. Rossi FM, Kringstein AM, Spicher A, Guicherit OM, Blau HM: Transcriptional control: rheostat converted to on/off switch. Mol Cell 2000, 6:723-728.

72. Barclay JL, Husse J, Bode B, Naujokat N, Meyer-Kovac J, Schmid SM, Lehnert H, Oster H: Circadian desynchrony promotes metabolic disruption in a mouse model of shiftwork. PLOS ONE 2012, 7:e37150.

73. Li XM, Delaunay F, Dulong S, Claustrat B, Zampera S, Fujii Y, Teboul M, Beau J, Levi F: Cancer inhibition through circadian reprogramming of tumor transcriptome with meal timing. Cancer Res 2010, 70:3351-3360.

74. Wu MW, Li XM, Xian L, Levi F: Effects of meal timing on tumor progression in mice. Life Sci 2004, 75:1181-1193.

75. Redman LM, Ravussin E: Caloric restriction in humans: impact on physiological, psychological, and behavioral outcomes. Antioxid Redox Signal 2011, 14:275-287.

76. Plunet WT, Streijger F, Lam CK, Lee JH, Liu J, Tetzlaff W: Dietary restriction started after spinal cord injury improves functional recovery. Exp Neurol 2008, 213:28-35.

77. Hasegawa A, Iwasaka H, Hagiwara S, Asai N, Nishida T, Noguchi T: Alternate day calorie restriction improves systemic inflammation in a mouse model of sepsis induced by cecal ligation and puncture. J Surg Res 2012, 174:136-141.

78. Jeong MA, Plunet W, Streijger F, Lee JH, Plemel JR, Park S, Lam CK, Liu J, Tetzlaff W: Intermittent fasting improves functional recovery after rat thoracic contusion spinal cord injury. J Neurotrauma 2011, 28:479-492.

79. Hou C, Bolt K, Bergman A: A general life history theory for effects of caloric restriction on health maintenance. BMC Syst Biol 2011, 5:78

80. Froy O, Chapnik N, Miskin R: Relationship between calorie restriction and the biological clock: lessons from long-lived transgenic mice. Rejuvenation Res 2008, 11:467-471.

81. Aguilera-Martínez R, Ramis-Ortega E, Carratalá-Munuera C, Fernández-Medina JM, Saiz-Vinuesa MD, Barrado-Narvión MJ: Enteral Feeding via Nasogastric Tube. Effectiveness of continuous versus intermittent administration for greater tolerance in adult patients in Intensive Care. JBI Libr Syst Rev 2011, 9:S218-S234

82. Campbell IT, Morton RP, Macdonald IA, Judd S, Shapiro L, Stell PM: Comparison of the metabolic effects of continuous postoperative enteral feeding and feeding at night only. Am J Clin Nutr 1990, 52:1107-1112.

83. Chen YC, Chou SS, Lin LH, Wu LF: The effect of intermittent nasogastric feeding on preventing aspiration pneumonia in ventilated critically ill patients. J Nurs Res 2006, 14:167-180.

84. Hiebert JM, Brown A, Anderson RG, Halfacre S, Rodeheaver GT, Edlich RF: Comparison of continuous vs intermittent tube feedings in adult burn patients. J Parenter Enteral Nutr 1981, 5:73-75.

85. MacLeod JB, Lefton J, Houghton D, Roland C, Doherty J, Cohn SM, Barquist ES: Prospective randomized control trial of intermittent versus continuous gastric feeds for critically ill trauma patients. J Trauma 2007, 63:57-61. 
86. Marshall A, West SH: Enteral feeding in the critically ill: Are nurse practices contributing to hypocaloric feeding? Int Crit Care Nursing 2006, 22:95-105.

87. McClave SA, Martindale RG, Vanek VW, McCarthy M, Roberts P, Taylor B, Ochoa JB, Napolitano L, Cresci G: Guidelines for the Provision and Assessment of Nutrition Support Therapy in the Adult Critically III Patient: Society of Critical Care Medicine (SCCM) and American Society for Parenteral and Enteral Nutrition (A.S.P.E.N.). J Parenter Enteral Nutr 2009, 33:277-316.

88. Steevens EC, Lipscomb AF, Poole GV, Sacks GS: Comparison of continuous vs intermittent nasogastric enteral feeding in trauma patients: perceptions and practice. Nutr Clin Pract 2002, 17:118-122.

doi:10.1186/1479-5876-12-79

Cite this article as: Sunderram et al:: Time-restricted feeding and the realignment of biological rhythms: translational opportunities and challenges. Journal of Translational Medicine 2014 12:79.

\section{Submit your next manuscript to BioMed Central and take full advantage of:}

- Convenient online submission

- Thorough peer review

- No space constraints or color figure charges

- Immediate publication on acceptance

- Inclusion in PubMed, CAS, Scopus and Google Scholar

- Research which is freely available for redistribution 